\title{
In Vitro Study for Nano Hydroxyl Apatite and Chitosan Coated Surface after Immersion in Simulated Body Fluid
}

\author{
Saja Kareem Esmael ${ }^{1}$, Raghdaa Kareem Jassim $^{2}$, Soodad Abdallah Al-Hiloh ${ }^{3}$ \\ ${ }^{1}$ Lecturer in Department of Prosthodontics, College of Dentistry, Uruk University, Baghdad, Iraq, ${ }^{2}$ Professor in \\ Department of Prosthodontics, College of Dentistry, University of Baghdad, Baghdad, Iraq, ${ }^{3}$ Lecturer Assistant in \\ Department of Prosthodontics, College of Dentistry, University of Kufa, Najaf, Iraq
}

\begin{abstract}
Multiple attempts are made to develop coating layers on the implant surface to enhance ossiointegration and support implant functions. The mixture of chitosan with HA prepared by sol-gel process to make organicinorganic hybrid composite that has the ability to make network with or without covalent bonds between components.

In this study the immersion of titanium disc coated via sol - gel technique by nano-HA and chitosan in simulated body fluid.

Materials and Method: Composite of nano hydroxy apatite/chitosan was prepared by sol - gel technique after preparation of two solutions of calcium nitride and phosphorous pentaoxide, then the magnetic stirrer was used for mixing of these solutions, then $3 \mathrm{mg}$ of chitosan were added to the mixture and the mixture was stirrer for 15 hours to complete the mixing. Dip coated of titanium samples, then the samples were removed and dried by hot air oven, finally samples were sintered at $400^{\circ} \mathrm{C}$ for one hour. Coated samples were immersed in SBF in closed containers and placed in incubators at temperature $37^{\circ} \mathrm{C}$ for 30 days.

Analysis of the surface include thickness measurement, X-ray diffraction (XRD), scanning electron microscopy (SEM) and energy-dispersive $\mathrm{x}$-ray spectroscopy (EDX).

The results of thickness measurement showed increase in thickness of the coated layer after immersion in SBF compared with thickness before immersion. The results of XRD showed the appearance of new peaks of HA, SEM showed there are additional accumulation of HA granules on the original coating layer. EDX test showed decreased in the concentration of the main ions component $(\mathrm{Ca}, \mathrm{Na}, \mathrm{P}, \mathrm{O}$ and $\mathrm{K}$ ) when compared with coated samples before immersion in SBF.
\end{abstract}

Keywords: Dental implant, dip coating, sol-gel, chitosan, hydroxyapatite, nanoparticles, simulated body fluid.

\section{Introduction}

The successful of dental implant depends on many factors; implant material, design of implant and design of implant surface ${ }^{(1)}$. Multiple attempts are made to develop coating layers on the implant surface to enhance ossiointegration and support implant functions ${ }^{(2)}$. The coating layer should be biocompatible and osteoconductive properties which mean that it must have the ability to attract osteoblasts to the implant surface and enhance bone formation to secure boneimplant interface ${ }^{(3)}$. The widely use of Titanium and its alloys as dental implant due to its biocompatibility, good strength, resistance to corrosion and has the ability to enhance ossiointegration ${ }^{(4)}$. Many researches have been done to modify titanium implant surface by coating with materials that enhance stabilization and ossiointegration $^{(5)}$. The hydroxy apatite is commonly used as coating for titanium implant; since it is biomaterial that resembles natural teeth and bones ${ }^{(6)}$. Also because of its biocompatibility that enhance growth of bone when implanted inside the body and acceptable mechanical properties so it is widely used as coating 
material in plastic and orthopedic surgery ${ }^{(7)}$. The sol-gel process can be successfully used in the preparation of HA powder or thin film under specific conditions ${ }^{(8)}$. Sol - gel is successful process to produce nano sized HA ${ }^{(9)}$. Several types of sol - gel coatings can be applied for examples; dip coating, spray coating, flow coating and spin coating, making it an ideal technique for production of biocompatible coating ${ }^{(10)}$. The use of dip coating procedure to apply the coating materials on titanium substrate has the advantage to change surface properties of the substrate and retaining the favorable properties of the coating material to the implant surface to accelerate ossiointegration $^{(11)}$. The mixture of chitosan with HA prepared by sol-gel process to make organic-inorganic hybrid composite that has the ability to make network with or without covalent bonds between components ${ }^{(12)}$. Chitosan as an amiopolysacharide that gained from alkaline deacetylation of chitin, it is a natural compound that characterized by its biocompatibility, biodegradability, non toxic and osteoconductive, so it has many medical applications; as surgical, reduction of periodontal pocket ${ }^{(13)}$ and as a material for bone grafting $^{(14) .}$ Many attempts have been made to develop chitosan hybrid by making composites that establish ability of forming bone-like apatite in simulated body fluid $(\mathrm{SBF})^{(15)}$. A cellular (SBF) that have ions concentrations almost similar to that of human plasma, it has the ability to formulate bone apatite on surface of the bioactive materials, therefore it used for in vitro estimation of the bioactivity of the materials and evaluation of the formation of bone like apatite on the implant surface ${ }^{(16)}$. The procedure of measure the HA formation on the coated surface considered as in vitro procedure that has many advantages over the conventional in vivo procedure in that is simplest, cheaper, quicker procedure, reproducible method and less effected by experimental conditions ${ }^{(17)}$. Fan et al, 2008 study the apatite formation on natural nano HA/ chitosane composite in simulated body fluid ${ }^{(18)}$. Rhee et al, 2012 study the synergic effect of silanol group and calcium ion in chitosan membrane on apatite forming ability in simulated body fluid ${ }^{(19)}$.

The study aimed to evaluate the formation of new hydroyapatite after immersion of coated samples in SBF.

\section{Materials and Method:}

Preparation of Sol-Gel: The preparation of nano HA/chitosan composite was achieved according to (Esmael et al, 2020) $^{(20) \text { : }}$
1. A magnetic stirrer ( $\mathrm{SH}-3$ /England) was used for mixing of $125 \mathrm{ml}$ of Ethyl alcohol and (10.78 gm) of Calcium nitride which was weighed by electronic balance (Germany, accuracy 0.0001g). Mixing was continued for one hour until completely dissolved of $\mathrm{Ca}\left(\mathrm{NO}_{3}\right)_{2}$ to prepare first solution.

2. Mixing of (5) mg phosphorous petaoxide $\mathrm{P}_{2} \mathrm{O}_{5}$ with (125) $\mathrm{ml}$ of Ethyl Alcohol for one hour on magnetic stirrer for completion of mixing and preparation of second solution.

3. Mixing of the two solutions was achieved by drop wise of the first solution on the second solution on magnetic stirrer for 2 hours, at this time (5) $\mathrm{mg}$ of $\mathrm{KOH}$ was added to complete the reaction.

4. Chitosan (3) mg was added to the mixture then mixed on magnetic stirrer for 15 hours.

Sample Preparation: Rod of commercially pure titanium grade 2 (Orotig S rl EU company Italy) were cut into circular discs with $10 \mathrm{~mm}$ diameter and $2.5 \mathrm{~mm}$ in thickness, the by the use of carbide silicone with 500 micron roughness for $15 \mathrm{~min}$ to provide mirror polished surface of samples. Then these discs were placed in ultrasound ethanol water bath absolute $\geq 99.8 \%$ for 15 min to remove debris and infection, finally discs were washed by distilled water for $10 \mathrm{~min}$ and left to dry at room temperature ${ }^{(21)}$.

Dip Coating Procedure: Titanium samples were immersed in the mixture of chitosan/HA sol - gel on slow speed magnetic stirrer and continue for $90 \mathrm{~min}$. to complete precipitation of the coating layer on samples, then the samples were removed from the mixture and dried by hot air oven ( $0 \_200$ c) (IMS/406, France).

Heat treatment (Sintering): The coated samples were sintered by the use of tube furnace (carbolite type MTF 12/38A. BAMFORD, England). Samples were coated at gel stage and sintered for $400^{\circ} \mathrm{C}$ for 1 hour.

Preparation of simulated body fluid (SBF): SBF prepared according to Kokubo's protocol ${ }^{(22)}$ with some modifications, the chemical composition of SBF and there quantity are listed in table (1).

Table (1) Chemical composition of SBF

\begin{tabular}{|l|c|}
\hline Description & Quantity gm/L \\
\hline $\mathrm{NaCl}$ & 8.036 \\
\hline $\mathrm{KCL}$ & 0.225 \\
\hline
\end{tabular}




\begin{tabular}{|l|c|}
\hline Description & Quantity gm/L \\
\hline $\mathrm{CaCl}_{2}$ & 0.293 \\
\hline $\mathrm{NaHCO}_{3}$ & 0.352 \\
\hline $\mathrm{K}_{2} \mathrm{HPO}_{4}$ & 0.230 \\
\hline $\mathrm{MgCl}_{2} \cdot 6 \mathrm{H}_{2} \mathrm{O}$ & 0.311 \\
\hline $\mathrm{Na} \mathrm{SO}_{4}$ & 0.072 \\
\hline
\end{tabular}

At room temperature all salts that are listed in table (1) are mixed with $1 \mathrm{~L}$ of distilled water on magnetic stirrer for 1 hour to ensure completely dissolving of salts in water, and then the $\mathrm{PH}$ of fluid was adjusted to 7.4 and checked by PH meter (Germany).

Immersion of samples in SBF: Coated samples are immersed in SBF, and then the containers should be closed and placed in incubator (Gallen bamp. England) at temperature of $37^{\circ} \mathrm{C}$ which is the temperature of human body ${ }^{(23)}$. And the fluid should be changed at the same time every day to preserve PH level (7.2-7.4) for 30 days, the early nucleation of apatite start after 24 hours of immersion ${ }^{(24)}$.

Analysis of the coated layer: After 30 days the samples were taken out of SBF and rinsed in distilled water and air dried then surface characterized by:

1. Thickness measurement: After removing of the coated samples from the SBF the coated layer was measured by microprocess coating thickness gauge (TF-C-UVIS-SR/U.S.A.), the mean of three readings was 90 um when compared with the

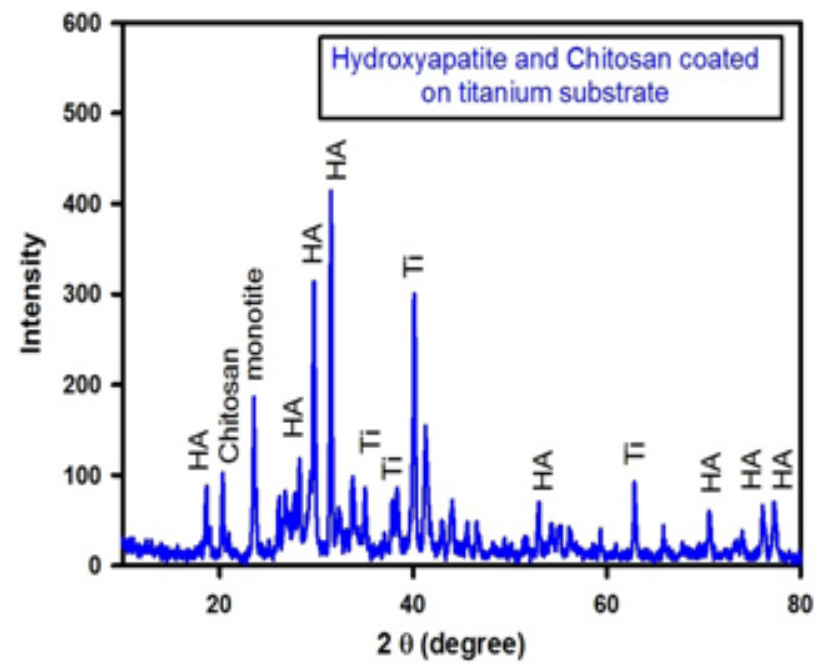

(a) thickness of coated samples before immersion in SBF was 60 um because of the formation of new layers of $\mathrm{HA}$ after immersion in $\mathrm{SBF}^{(25)}$.

2. X-Ray diffraction analysis: The chemical composition of crystallographic structure was tested by this analysis test, the indexing peaks based on the joint committee on powder diffraction standards. (JCPDS). The device used (SHIMAZU, XRD6000, Japan).

\section{Structural surface characterization by SEM:}

The device used for this test was (SEM TE scan vega 111, Czech). This test analysis was of two parts:

- Surface Analysis: The surface morphology and topographical characteristics of coated sample was performed by scanning electron microscope (SEM) after 30 days of immersion in SBF.

- Material characterization: By Energy dispersive spectroscopy (EDS) by the use of SEM machine for chemical analysis of the sample, it depends on interaction and excitation of $\mathrm{x}$ - ray by each sample.

\section{Results}

X-ray diffraction analysis: As appeared in fig. $3.1 \mathrm{a}$ and $\mathrm{b}$ compared between coated samples before and after immersion in SBF for 30 days that illustrate the appearance of new peaks of HA. Peaks of HA were indexed according to the standard pattern (JCPDS09-0432).

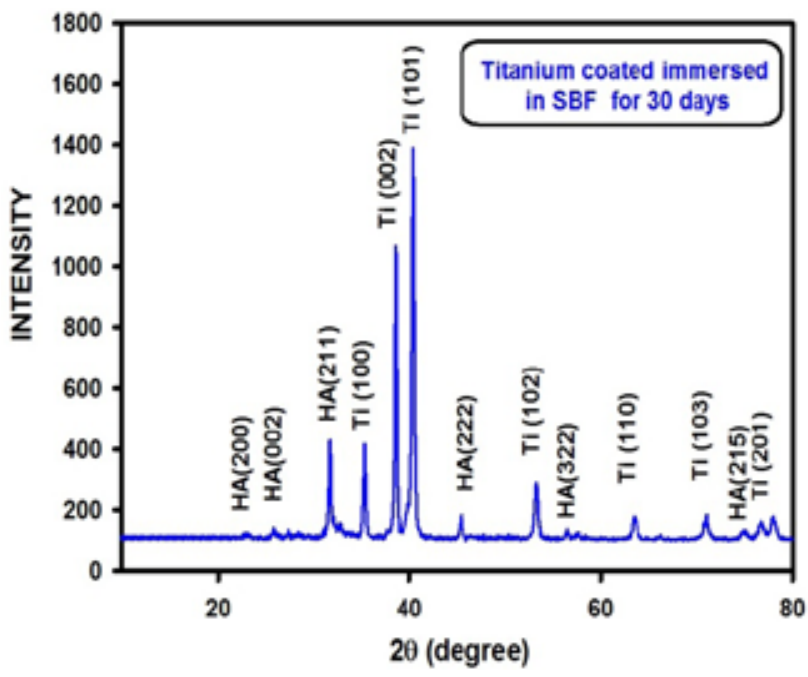

(b)

Fig. (3.1) X-ray diffraction of tested samples 
3.2. Scanning electron microscope (SEM): The surface feature of coated samples after 30 days immersed in SBF was compared with surface feature of coated samples before immersion in SBF. As appeared in fig. $3.2 \mathrm{a}, \mathrm{b}$ and $\mathrm{c}$ there are additional accumulation of HA granules on the original coating layer. The newly formed crystals of HA accumulated as layers of flaks which differed from the manner of accumulation before immersion in SBF which was spherical like granules, these differences in the manner of accumulation due to the differences in the condition, $\mathrm{PH}$ and temperature of $\mathrm{HA}$ formation. Also the sufficient time of immersion in SBF leaded to completely coverage of titanium samples with layers of HA even cracks areas and appearance of randomly accumulation of layers because of unrestricted formation and growth of HA crystals ${ }^{(26)}$. This manner of nucleation and formation of new apatite is an indication of bioactivity of the coated sample ${ }^{(27)}$.
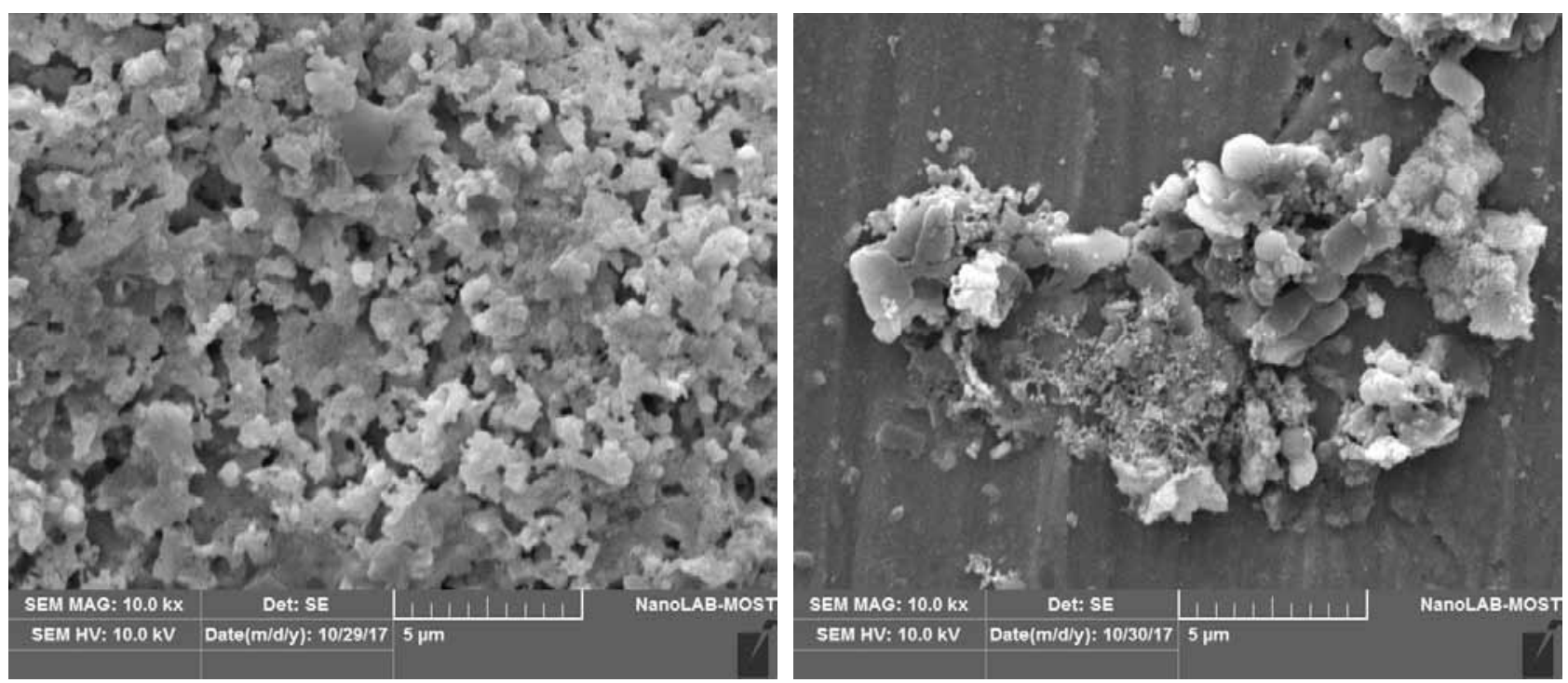

Fig. (3.2) a SEM (5 um)
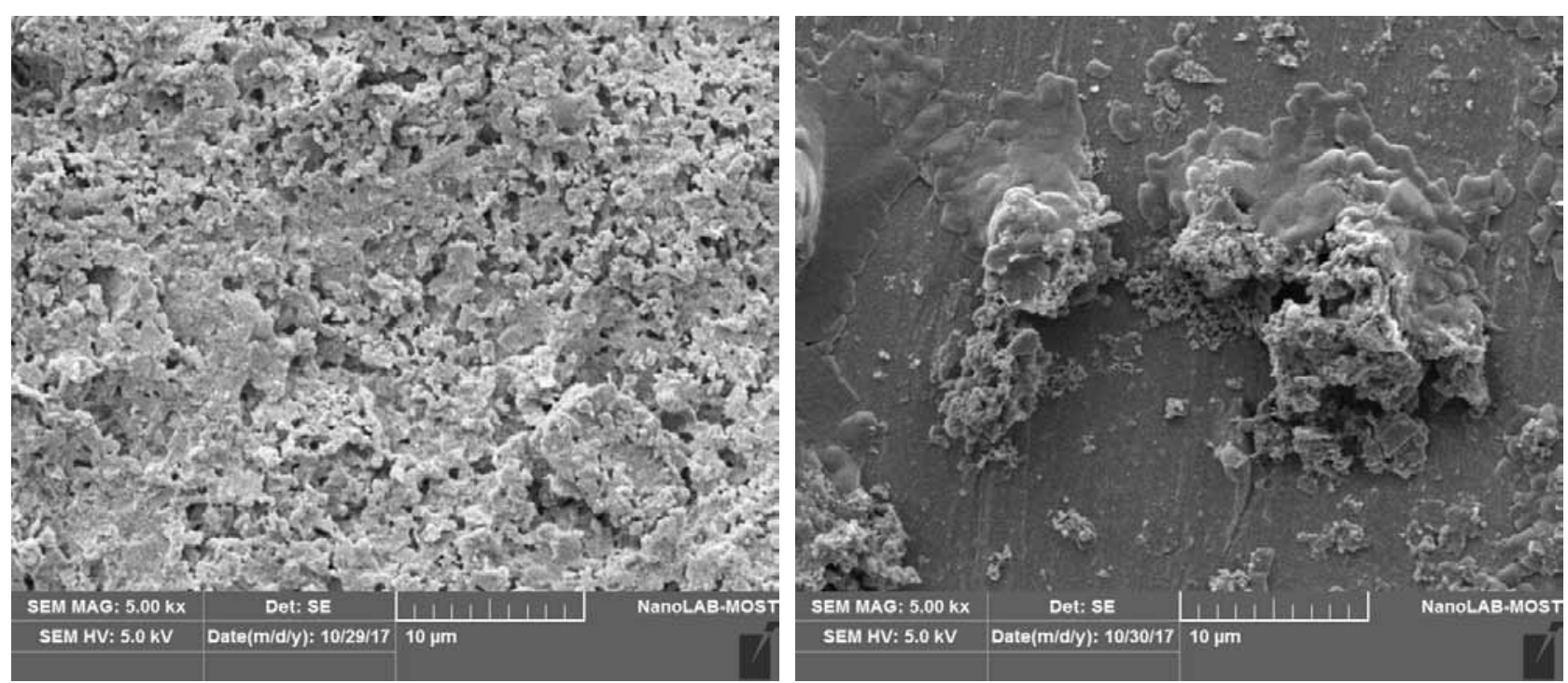

Fig. (3.2) b SEM (10 um) 

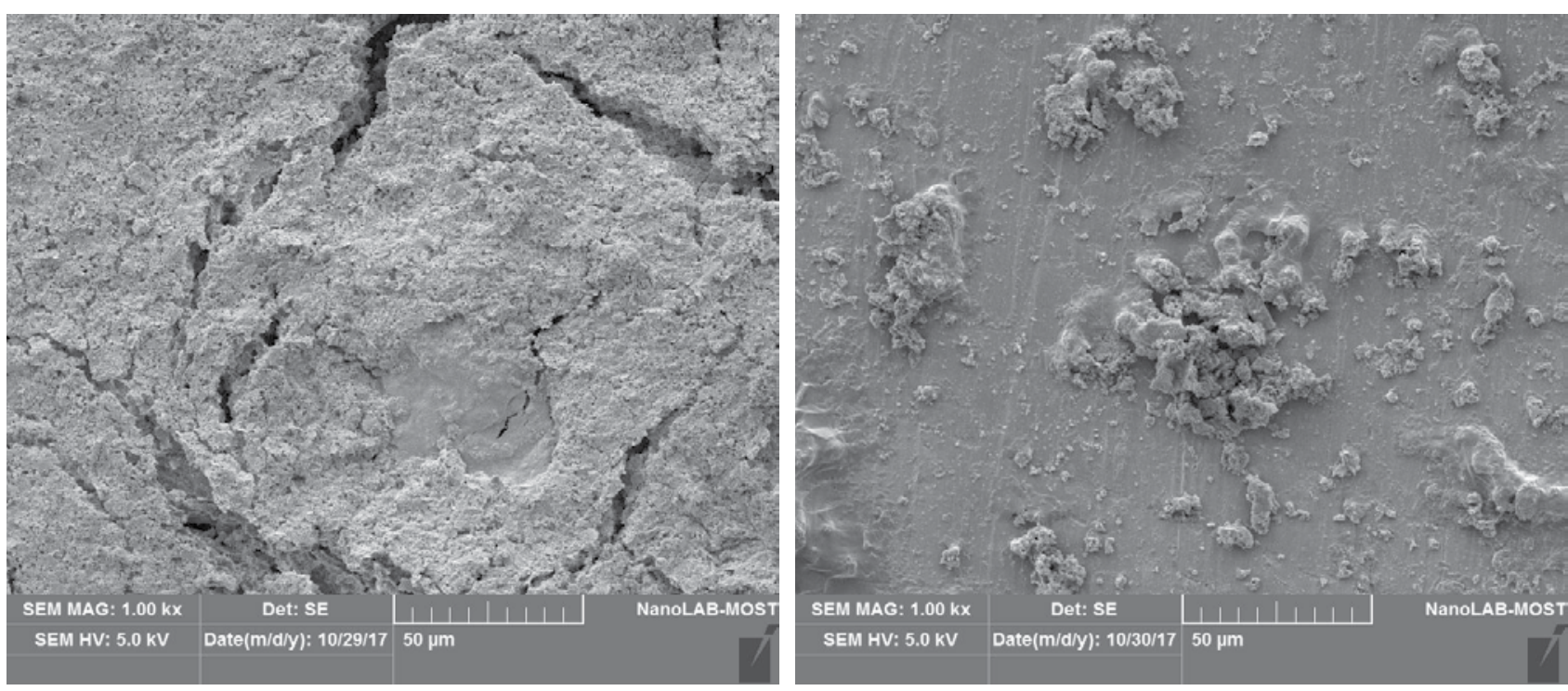

Fig. (3.2) c SEM (50um)

Energy dispersive $x$-ray spectroscopy (EDX): This test depended on the interaction of $\mathrm{x}$-ray with each element, as seen in fig. (3.3) a the main component of the plate $\mathrm{Ca}, \mathrm{Na}, \mathrm{P}, \mathrm{O}$ and $\mathrm{K}$. showed decreased in concentration of these ions when compared with fig. (3.3) $b$ that showed EDX of coated sample before immersion in SBF.

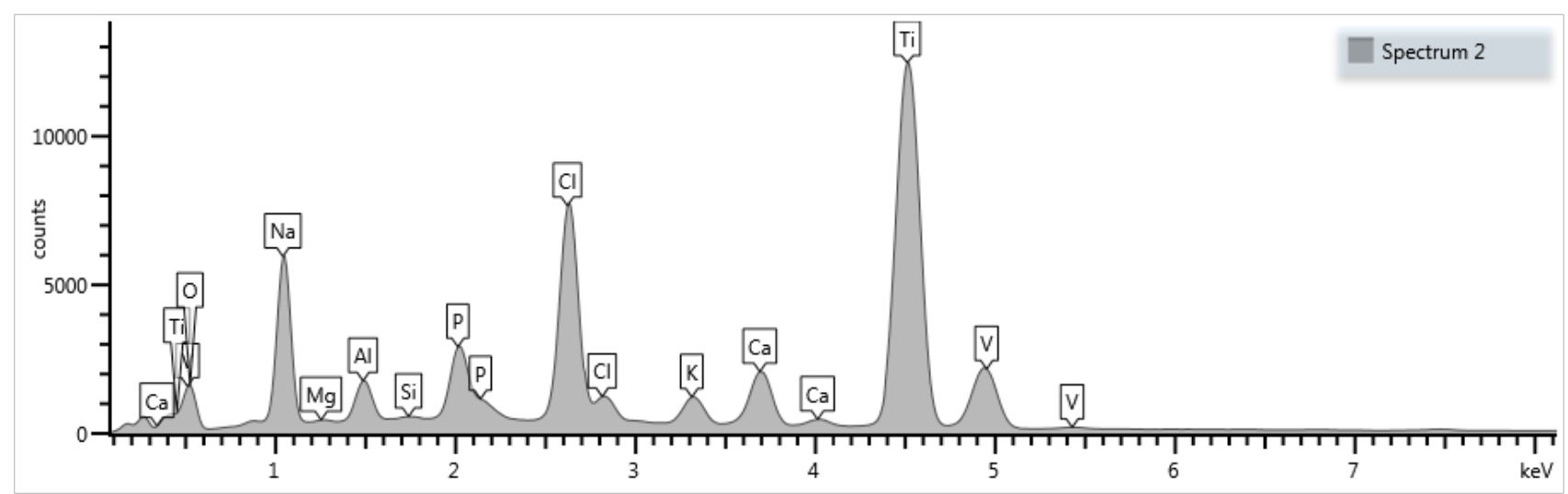

\begin{tabular}{|l|c|c|}
\hline Element & $\mathbf{W t} \%$ & Wt\% Sigma \\
\hline $\mathrm{O}$ & 19.20 & 0.39 \\
\hline $\mathrm{Na}$ & 14.11 & 0.12 \\
\hline $\mathrm{Mg}$ & 0.20 & 0.03 \\
\hline $\mathrm{Al}$ & 2.24 & 0.04 \\
\hline $\mathrm{Si}$ & 0.14 & 0.03 \\
\hline $\mathrm{P}$ & 3.34 & 0.05 \\
\hline $\mathrm{Cl}$ & 11.44 & 0.08 \\
\hline $\mathrm{K}$ & 1.86 & 0.04 \\
\hline $\mathrm{Ca}$ & 3.89 & 0.05 \\
\hline $\mathrm{Ti}$ & 41.72 & 0.23 \\
\hline $\mathrm{V}$ & 1.86 & 0.08 \\
\hline Total & $\mathbf{1 0 0 . 0 0}$ & \\
\hline
\end{tabular}

Fig. (3.3) a EDX of coated sample after 30 


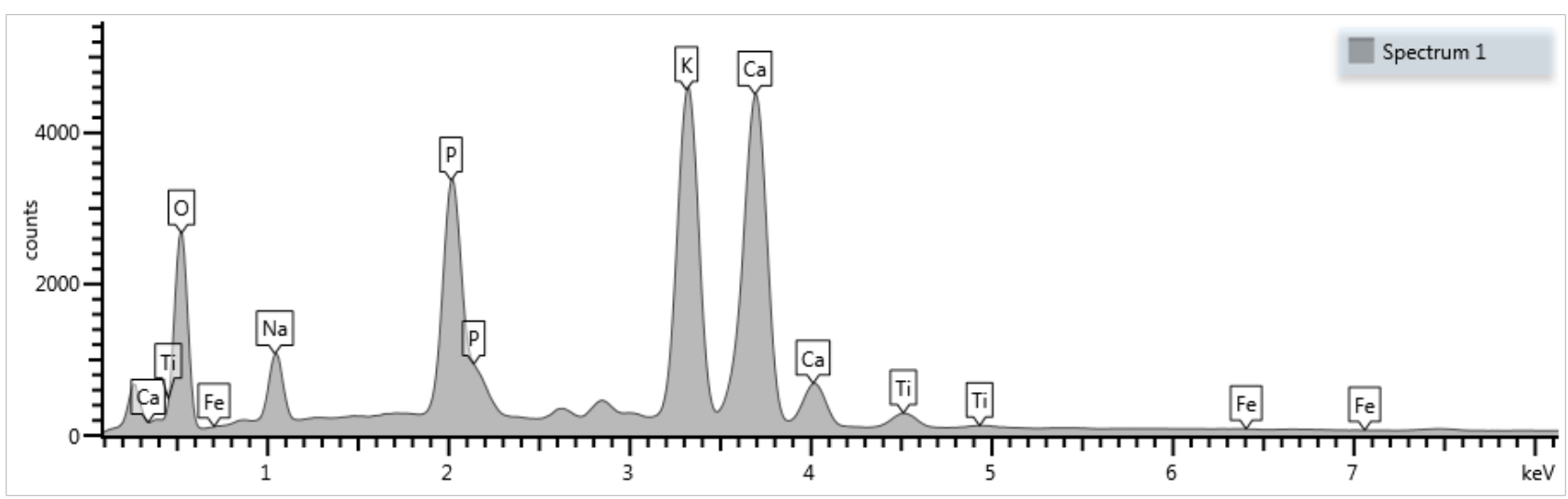

\begin{tabular}{|l|c|c|}
\hline Element & Wt $\%$ & Wt\% Sigma \\
\hline $\mathrm{O}$ & 49.00 & 0.33 \\
\hline $\mathrm{Na}$ & 4.51 & 0.10 \\
\hline $\mathrm{P}$ & 7.91 & 0.10 \\
\hline $\mathrm{K}$ & 17.05 & 0.14 \\
\hline $\mathrm{Ca}$ & 20.03 & 0.17 \\
\hline $\mathrm{Ti}$ & 1.37 & 0.06 \\
\hline
\end{tabular}

Fig. (3.3) b EDX of coated sample days immersion in SBF before immersion in SBF

\section{Discussion}

Chitosan material recently has been used in dental implant because of its biocompatibility and bioactivity with the natural tissue ${ }^{(28)}$. It has the ability to successfully coating of titanium but doesn't have ability of new apatite formation, therefore hybridization of chitosan with nano HA prepared by sol - gel technique to form chitosan/HA composite to enhance formation of new apatite ${ }^{(29)}$. The nano HA prepared by sol - gel technique have hydroxyl groups on its surface that act as nucleation that promote nucleation of calcium and phosphate that facilitate ossiointegration $^{(30)}$. Coated samples were immersed in SBF to observe nucleation ability of biomaterials ${ }^{(31)}$.

Financial Disclosure: There is no financial disclosure.

Conflict of Interest: None to declare.

Ethical Clearance: All experimental protocols were approved under the College of Dentistry and all experiments were carried out in accordance with approved guidelines.

\section{References}

1. Fawad J, Hameeda B, Roberto C, Georgios E. Romanos4: Role of primary stability for successful osseointegration of dental implants: Factors of influence and evaluation, Interventional Medicine \& Applied Science. 2013; 5 (4): 162-167.

2. Bobyn J, Thompson R, Lim L. Local alendronic acid elution increases net periimplant bone formation: A micro-CT analysis. Clin. Orthop. Relat. Res. 2014; 472: 687-694.

3. Albrektsson T, Johansson C. Osteoinduction, osteoconduction and osseointegration. Eur. Spine J. 2001; 10: S96-S101.

4. Yang Y, Kim KH, Ong JL. A review on calcium phosphate coatings produced using sputtering process-An alternative to plasma spraying. Biomaterials. 2005;26: 327-337.

5. Yang $\mathrm{Y}$, Oh N, Lui Y. Enhancement of osseointegration using surface modified titanium implant. JOM. 2006;58: 71-76.

6. Chou BY, Chang E. Influence of deposition temperature on mechanical properties of plasmasprayed hydroxyapatite coating on titanium alloy with $\mathrm{ZrO} 2$ intermediate layer. J Therm Spray Technol 2003; 12: 199-207.

7. Arnould C, Denayer J, Planckaert M, Delhalle J, Mekhalif $\mathrm{Z}$. Bilayers coating on titanium surface: the impact on the hydroxyapatite initiation. J Colloid Interface Sci 2010; 341: 75-82. 
8. Sarbjit K, Niraj B, Charu K. Preparation and Deposition of Hydroxyapatite on Biomaterials by Sol-Gel Technique-A Review Chitkara Chemistry Review.2013; 1: 59-69

9. Xia W, Chang J. Preparation and characterization of nano-bioactiveglasses (NBG) by a quick alkalimediated sol-gel method. Materials Letters.2007; 61: 3251-3253.

10. Catauro M, Bollino F, Papale F. Influence of the polymer amount on bioactivity and biocompatibility of $\mathrm{SiO} 2 / \mathrm{PEG}$ hybrid materials synthesized by solgel technique. Mater. Sci. Eng. 2015a; C 48: 548555.

11. Catauro M, Bollino F, Papale, F. Synthesis of $\mathrm{SiO} 2$ system via sol-gel process: biocompatibility tests with a fibroblast strain and release kinetics. J. Biomed. Mater. Res., Part A.2014a; 102: 16771680.

12. Ferreira-Neto E, Carvalho F, Ullah S. Surface structure and reactivity study of phosphotungstic acid-nitrogenated ormosils. J. Sol-Gel. Sci. Technol. 2013; 66: 363-371.

13. Di Martino A, Sittinger M, Risbud MV. Chitosan: a versatile biopolymer for orthopedic tissueengineering. Biomaterials 2005; 26:5983-90.

14. I. Yamaguchi, S. Iizuka, A. Osaka, H. Monma and J. Tanaka, the effect of citric acid addition on chitosan/hydroxyapatite composites Colloid. Surf. A 214, 111 .

15. SH Rhee, YK Lee, BS Lim. Evaluation of chitosan nano - hybrid material containing silanol group and calcium salt as a bioactive bone graft Key Eng. Mater. 2005; 284-286, 765.

16. Kong L J, Gao Y, Lu G Y, et al. A study on the bioactivity of chitosan/nano-hydroxyapatite composite scaffolds for bone tissue engineering. European Polymer Journal, 2006; 42(12): 31713179 .

17. Lee J, Leng Y, Choe, K, Ren F.; Ge X. Cell culture medium as an alternative to conventional semmulated body fluid, Acta Biomaterialia, 2011; 7:2615 - 22 .

18. Yong-bin F, Xiao-ying LU.A study of apatite formation on natural nano-hydroxyapatite/chitosan composite in simulated body fluid, Mater.Sci, 2008; 2(1): 91-94.

19. Sang-Hoon R, Seung J, Junzo T. Synergistic effect of silanol group and calcium ion in chitosan membrane on apatite forming ability in simulated body fluid, 2012; 17:3: 357-368.

20. Saja Kareem Esmael, Raghdaa Kareem Jassim, Rasha Mahdi, Preparation and Characterization of Nano-Hydroxyapatite Particles and Chitosan by Sol-Gel Method (in Vitro Study) Indian Journal of Forensic Medicine \& Toxicology, April-June 2020, Vol. 14, No. 2, P(593 - 599).

21. Raghdaa K Jassim1, Zena Ali Abdul Rahman and Abdalbasit A Fatihallah. The Effect of Implant Screw Coating with Nano-Hydroxyapatite and Magnesium Chloride Mixture on Osseointegration: Biomechanical and Histological Study, International Journal of Medical Research \& Health Sciences, 2017, 6(11): 41-53

22. Kokubo, T., Takadama, H., How useful is SBF in predicting in vivo bone bioactivity, Biomaterials, 2006; 27: 2907-2915.

23. Gurrappa I, Kiran Kumar M. Evaluation of corrosion resistance of plasma sprayed alumina, magnesia stabilized zirconia and yttria stabilized zirconia coatings on 316 stainless steel for biomedical applications. Proceedings of Global 2000 Corrosion Meet, Mumbai, India, vol. 1. Quest Publications, Mumbai; 2000. p. 561- 72.

24. Ryo H, Hirotaka M, Hikaru S, Yuki S. structural effects of phosphate groups on apatite formation in copolymer modified with $\mathrm{Ca}^{2+}$ in a simulated body fluid, J. Mater. Chem. B, 2018, 6, $174-182$.

25. Jonasova L, Muller FA, Helebrant A, Strnd J and Greil P, Biometric apatite formation on chemically treated titanium, Biomaterials, 2004, Mar - April; 25 (7 - 8): 1187-94.

26. Lu X, Leng Y. Theoretical analysis of calcium phosphate precipitation in simulated body fluid. Biomaterials 2005;26:1097-108.

27. Kaneko H, Uchida M, Kim HM, Kokubo T, Nakamura T. Process of apatite formation induced by anatase on titanium metal in simulated body fluid. Key Eng Mater 2002; 218-220:649-52.

28. Zhang Y, Zhang M. Synthesis and characterization of macroporous chitosan/calcium phosphate composite scaffolds for tissue engineering. J Biomed Mater Res 2001;55:304-12.

29. Qiaoling Hu, BaoqiangLi, Mangwang, Jiacong Shen, preparation and characterization of biodegradable chitosan/hydroxyapatite nanocomposite rods via in situ hybridization : a potential material as internal 
fixation of bone fracture. Biomaterials 25 (5), 779 785, 2004.

30. Catauro, M., Bollino, F., Papale, F., Mozetic, P., Rainer, A., Trombetta, M, Biological response of human mesenchymal stromal cells to titanium grade 4 implants coated with $\mathrm{PCL} / \mathrm{ZrO} 2$ hybrid materials synthesized by sol-gel route: In vitro evaluation. Mater. Sci. Eng., C 2014e, 45, 395-401.

31. Barrere F, Snel MM, Van Blitterswijk CA, DeGroot K, Layrolle P., Nano - scale study of nucleation and growth of calcium phosphate coating on titanium implants. Biomaterials, 2004: 25(14):2901 - 10. 